INFLAMMATORY BOWEL DISEASE

\title{
Influence of dietary factors on the clinical course of ulcerative colitis: a prospective cohort study
}

\author{
S L Jowett, C J Seal, M S Pearce, E Phillips, W Gregory, J R Barton, M R Welfare
}

Gut 2004;53:1479-1484. doi: 10.1136/gut.2003.024828

See end of article for authors' affiliations

Correspondence to:

DrM R Welfare, University

of Newcastle, North

Tyneside Hospital, Rake

Lane, North Shields, Tyne

and Wear NE29 8NH,

UK; mark.welfare@

northumbria-healthcare.

nhs.uk

Revised version received 10 March 2004

Accepted for publication

25 March 2004
Background and aims: The causes of relapses of ulcerative colitis (UC) are unknown. Dietary factors have been implicated in the pathogenesis of UC. The aim of this study was to determine which dietary factors are associated with an increased risk of relapse of UC.

Methods: A prospective cohort study was performed with UC patients in remission, recruited from two district general hospitals, who were followed for one year to determine the effect of habitual diet on relapse. Relapse was defined using a validated disease activity index. Nutrient intake was assessed using a food frequency questionnaire and categorised into tertiles. Adjusted odds ratios for relapse were determined using multivariate logistic regression, controlling for non-dietary factors.

Results: A total of 191 patients were recruited and $96 \%$ completed the study. Fifty two per cent of patients relapsed. Consumption of meat (odds ratio (OR) 3.2 (95\% confidence intervals (CI) 1.3-7.8)), particularly red and processed meat (OR 5.19 (95\% Cl 2.1-12.9)), protein (OR 3.00 (95\% Cl 1.25-7.19)), and alcohol (OR 2.71 (95\% Cl 1.1-6.67)) in the top tertile of intake increased the likelihood of relapse compared with the bottom tertile of intake. High sulphur (OR $2.76(95 \% \mathrm{Cl} 1.19-6.4)$ ) or sulphate (OR 2.6 (95\% Cl 1.08-6.3)) intakes were also associated with relapse and may offer an explanation for the observed increased likelihood of relapse.

Conclusions: Potentially modifiable dietary factors, such as a high meat or alcoholic beverage intake, have been identified that are associated with an increased likelihood of relapse for UC patients. Further studies are needed to determine if it is the sulphur compounds within these foods that mediates the likelihood of relapse and if reducing their intake would reduce relapse frequency.
$\mathrm{T}$ he course of ulcerative colitis (UC) is variable but the majority of patients follow a relapsing and remitting course. ${ }^{1}$ The underlying causes of relapses of UC have not been clearly defined. Three prospective studies have identified factors that predict an increased likelihood of relapse..$^{-4}$ Relapse was more likely to occur with higher relapse frequency, ${ }^{3}$ less time since last relapse, ${ }^{3}$ or a higher total number of previous relapses, ${ }^{4}$ at least in women. ${ }^{2}$ These observations do not allow patients to modify any factors that may be contributing to a high relapse frequency.

Several studies ${ }^{5-9}$ have examined the association between dietary factors and onset of UC but none have systematically examined the relationship between normal dietary intake and relapses of UC. A high intake of dairy products or low dietary fibre intake may be associated with relapse ${ }^{10-14}$ but the strongest evidence for a dietary factor is that sulphur and sulphate may be implicated in relapse of colitis.

The role of sulphur rich compounds was first suspected from animal models where sulphated dextrans, but not dextrans without sulphur, were able to induce experimental colitis in rodents. ${ }^{15}$ The toxic effects of sulphur reducing compounds, particularly hydrogen sulphide, at concentrations commonly found in the lumen of the human colon, appear to be mediated through impaired utilisation of butyrate by colonocytes. ${ }^{16}$ Hydrogen sulphide causes increased epithelial permeability, loss of barrier function, ${ }^{17}$ cellular proliferation, ${ }^{18}$ and histological changes in rat colon that are similar to those seen in humans with UC. ${ }^{19}$ UC patients have significantly higher luminal concentrations of hydrogen sulphide than controls ${ }^{20}$ and disease activity correlates with sulphide production rates. ${ }^{21}$ Endogenous sources do not seem to make a significant contribution to the colonic pool of sulphur. ${ }^{22}$ The major exogenous sources of sulphur are the sulphur amino acids (found in high protein foods such as red meat, cheese, milk, fish, nuts, and eggs) and inorganic sulphate (in Brassica vegetables and as preservatives in processed foods, particularly commercial breads, beers, sausages, and dried fruit $^{23}$ ). Sulphur amino acids and inorganic sulphate reach the colon where they are converted to sulphides by fermentation with colonic bacteria or by sulphate reducing bacteria. ${ }^{24}{ }^{25}$ Faecal hydrogen sulphide concentration is increased by increasing either the sulphur amino acid content (as meat ${ }^{26}$ or sulphate content (as additives) of the diet. ${ }^{27}$ Generation of hydrogen sulphide by sulphate reducing bacteria is modest compared with total faecal sulphide concentration, ${ }^{20}$ suggesting that fermentation of sulphur amino acids may be the more important of the two mechanisms of generation of hydrogen sulphide. In a pilot study in which the intake of sulphur amino acids was limited, clinical improvement, in terms of stool frequency, was demonstrated in all four participants with UC. ${ }^{28}$

The aim of this study was to determine if any dietary factors postulated to influence disease activity, including dairy products, dietary fibre, and foods rich in sulphur, were associated with an increased likelihood of relapse in patients with UC.

\section{METHODS \\ Design}

This was an observational prospective cohort study in which patients with UC in clinical remission were followed for one year to determine the effect of diet on relapse. The outcome

Abbreviations: $F F Q$, food frequency questionnaire; $B M R$, basal metabolic rate; PAL, physical activity level; SCCAl, simple clinical colitis activity index; $O R$, odds ratio; UC, ulcerative colitis; IQR, interquartile range 
was clinical relapse or continued remission over the year, determined by a validated disease activity index.

\section{Setting}

Participants were recruited from two district general hospitals in the North East of England. The study had approval from the two local ethics committees.

\section{Participants}

Potential participants were identified between January and September 2000 through two existing databases of UC patients, compiled from histology reports or recruited from outpatient clinics and including patients currently under primary and secondary care. Inclusion criteria were: age 1870 years; diagnosis of UC (including proctitis) established by histology with extent determined by endoscopy or barium enema; ability to give informed consent; in remission at the time of recruitment; and last relapse more than one month prior to recruitment. Exclusion criteria were active disease or pregnancy, previous colectomy, or inability to comply with weekly postal follow up.

Eligible patients gave informed consent for the study and were interviewed by one of the authors (SLJ) at recruitment. In addition to the dietary assessment, data were collected on participant non-dietary factors that could potentially alter the risk of relapse, including age and sex, disease duration and extent, smoking status, medication, prior appendectomy, and baseline disease activity, which included a disease activity score, duration of remission, and previous relapse frequency.

\section{Measurement and validation of nutritional intake}

Habitual dietary intake was measured using a food frequency questionnaire (FFQ) listing 107 types of food (for instance, "bread and rolls") commonly consumed in the UK, and a food atlas that contained pictorial representations of different portions of food and a range of foods not readily described using standard household measures. ${ }^{29}{ }^{30}$ The FFQ and food photographs have been used in studies with healthy volunteers, ${ }^{29}$ alcoholic subjects, ${ }^{31}$ and cancer patients. ${ }^{32}{ }^{33}$ For each food, a series of eight photographs has been validated to accurately represent portions from the 5 th to the 95th centile of the distribution curve of UK portion sizes. ${ }^{34-36}$

Dietary intake was converted to nutrient intake depending on the specific type, amount, and preparation of food consumed, using a computerised food table (the UK Nutrient Databank, updated and modified by the Human Nutrition Research Centre, University of Newcastle (version 1.04)) derived from McCance and Widdowson's food composition tables, fifth edition with supplements. ${ }^{37-42}$ This provides data on more than 40 composite nutrients, including macro and micronutrients, of nearly 5000 foods eaten in the UK and on their food groups. Food groups were allocated by the Royal Society of Chemistry classification, which categorises foods into food groups such as "meat and meat products" or "milk and dairy products", and subgroups such as "red and processed meat", which are major sources of sulphur amino acids and sulphate.

The food table provides data on the sulphur composition of some, but not all, foods. Sulphur content was listed for $29 \%$ of the foods consumed by subjects in this study. For the sulphate content of foods, data were derived from a published source ${ }^{23}$ and added to the tables using mean values. The sulphate content of composite food and meals was calculated from the individual components using standard recipes. Using this method, sulphate values were assigned to $91 \%$ of foods reported by volunteers.

The FFQ was further validated by comparing reported energy intake and estimated energy requirements. Schofield equations $^{43}$ were used to determine the patient's basal metabolic rate (BMR), and from this a physical activity level (PAL) was calculated. PAL is the ratio by which actual energy intake is greater than BMR. PAL for an individual usually lies within the range $1.14-2.11 . .^{44}$

\section{Defining relapse and remission}

The outcome measure for the study was having a relapse or maintaining remission during the year from recruitment. Because of the need for a non-invasive method of defining relapse or remission in this relatively large cohort followed in the community, the simple clinical colitis activity index (SCCAI) was the chosen outcome measure. ${ }^{46}$ This is a symptom based disease activity index that uses six clinical parameters: daytime and nocturnal bowel frequency, urgency, amount of blood in the stool, wellbeing, and extraintestinal manifestations. The index has been validated as a measure of disease activity in UC by comparison with pre-existing disease activity indices ${ }^{46}$ and by its ability to discriminate between different degrees of disease activity. ${ }^{47}$ We have previously shown, in a separate cohort of participants, that a score of 5 or more accurately confirms a clinician defined relapse with $92 \%$ sensitivity, $93 \%$ specificity, $88 \%$ positive predictive value, and $95 \%$ negative predictive value when the questionnaire is self administered. ${ }^{47}$ Conversely, a score of less than 5 defines remission with a sensitivity of $93 \%$ and a specificity of $92 \%$.

To monitor disease activity, participants completed the six questions that made up the SCCAI and recorded their answers on preprinted stamped addressed postcards, which were returned to the study centre weekly. If a participant's score reached 5 or more, they were classified as having had a relapse. Sigmoidoscopies were not performed to confirm relapse because we had previously shown strong correlation between sigmoidoscopy and the SSCAI in defining relapse/ remission and because we wished to maximise patient participation so that the results would be more generalisable. Similarly, because a previous study suggested that the definition of relapse used had a positive predictive value of $88 \%,{ }^{47}$ stool cultures to exclude infectious agents were not performed to improve participation rates.

\section{Statistical analysis}

Nutrient data were not adjusted to energy intake because comparison of gross intake of nutrients is important in a disease such as UC where the colon is directly exposed to products of digestion. Furthermore, the relationship between certain nutrients and total energy intake is not clearly correlated and therefore adjusting nutrient intake proportionally to energy intake is likely to introduce distortions in the data ${ }^{48}$ Nutrient intake was compared for macronutrients (energy, fat, protein, carbohydrate, and alcohol), the Royal Society of Chemistry food groups, dietary fibre (measured as non-starch polysaccharide), sulphur, and sulphate intake. Nutrient data were categorised into tertiles, as is customary in many nutritional epidemiological studies. ${ }^{49}$ However, as this may in itself introduce bias into the analysis, results are also presented using a linear term for dietary intake.

Dietary and non-dietary characteristics of patients who relapsed were compared with those who remained in remission using multivariate logistic regression. We initially examined the effect of potentially important non-dietary confounding factors: age, sex, disease extent and duration, baseline SCCAI score, number of relapses in the year prior to recruitment, time since last relapse, average annual relapse frequency, medication use, including non-steroidal antiinflammatory drugs, smoking status, and prior appendectomy. The effect of each dietary factor was then examined, after controlling for the non-dietary confounders that had been found to be statistically significant and may additionally 
Table 1 Non-dietary characteristics of all patients at recruitment that were associated with relapse in a multivariate logistic regression analysis

\begin{tabular}{lll}
\hline & OR $(95 \% \mathrm{Cl})$ & LRT p \\
\hline SCCAl score at recruitment & & $<0.0001$ \\
0 & 1.00 & \\
1 & $1.46(0.67-3.18)$ & \\
2 & $5.28(2.00-14.0)$ & \\
3 or 4 & $9.30(3.50-24.7)$ & \\
Age (per 10 years) & $0.74(0.59-0.96)$ & 0.021 \\
\hline
\end{tabular}

SCCAI, simple clinical colitis activity index. ${ }^{46}$

OR $(95 \% \mathrm{CI})$, odds ratio ( $95 \%$ confidence interval).

$\mathrm{p}$ value from likelihood ratio test (LRT).

act as a surrogate for unidentified non-dietary factors that may increase the likelihood of a relapse, plus sex, which is a potentially important determinant of dietary intake. Statistical significance was assessed using likelihood ratio tests. Odds ratios (OR) and corresponding 95\% confidence intervals (CI) are reported. The fit of the logistic regression models to the data was assessed using the Pearson $\chi^{2}$ goodness of fit test. Statistical analysis was performed using SPSS statistical package version 10 (SPSS Inc., Chicago, Illinois, USA).

No correction has been made for multiple analyses. Allowance for multiple analyses can be made formally with statistical methods such as Bonferroni correction. However, the validity of correcting $\mathrm{p}$ values for the number of analyses performed has been questioned and it has been suggested that this can lead to rejection of true associations. ${ }^{50}{ }^{51}$ Another approach is to evaluate the results with respect to the strength of the association, the biological plausibility, and any supporting evidence.

\section{RESULTS}

\section{Recruitment and patient demographics}

A total of 463 patients were invited by letter to participate in the study. Replies were received from 355 , a $77 \%$ response rate. Of those who responded, 83 actively declined participation in the study and a further 81 were found to have exclusion criteria. Therefore, 191 participants were recruited to the study. There was no significant difference between participants and non-participants for age ( 2 years 6 months; $\mathrm{p}=0.071$, Student's $t$ test $)$ or $\operatorname{sex}\left(\mathrm{p}=0.759, \chi^{2}\right.$ test $)$.

Eight participants failed to complete the study: one withdrew because she was pregnant, one because she was receiving chemotherapy for breast carcinoma, one participant had a prophylactic colectomy because of a high risk of malignancy, and five participants were lost to follow up. Complete follow up data were therefore available on 183 (96\%) consented eligible participants. Subsequent statistical analyses were limited to these patients. Median age of participants was 51 years (interquartile range (IQR) 3861 years) and 93 were male (51\%). Median disease duration since hospital diagnosis was 6 years 7 months (IQR 2 years 10 months to 16 years 4 months). Disease extent was: proctitis $25.1 \%$, rectosigmoiditis $34.4 \%$, left sided disease $16.4 \%$, and extensive disease $24.1 \%$. At recruitment, 141 patients $(74 \%)$ were using regular 5-aminosalicylic acid drugs. In a randomly chosen subgroup of 50 patients who relapsed, continued reported compliance with 5-aminosalicylic acid drugs was high (96\%). Ninety six participants $(52 \%)$ were defined as having had a relapse during the year of follow up because their SCCAI score reached 5 or more. As previously reported, 68 of the patients were assessed in detail to check the performance of the SCCAI in this population by comparison with their reported relapse or remission status. ${ }^{47}$ Over the whole study, the SCCAI had $85.7 \%$ sensitivity and $84.8 \%$ specificity for defining relapse.

\section{Validation of nutritional assessment}

One hundred and twenty two patients $(67 \%)$ had a PAL within the acceptable limits for an individual. Twenty four patients (13\%) appeared to underreport energy intake based on PAL and $36(20 \%)$ appeared to overreport. One patient's PAL was unavailable as their weight was not recorded.

\section{Non-dietary differences}

On multivariate analysis, non-dietary factors that were significantly different between patients who relapsed and those that remained in remission were disease activity score at recruitment, as measured by the SCCAI, and age (table 1). Relapse was more likely in those whose disease showed greater activity prior to recruitment and in younger patients. Other non-dietary variables that were examined, including use of prophylactic 5-aminosalicylic acid medication, were not statistically different between relapsers and those that remained in remission (75\% $\vee 79 \%$ for use of prophylactic medication; $\mathrm{p}=0.488, \chi^{2}$ test).

\section{Dietary differences}

Nutrient intake was compared for each of the macronutrients, food groups, dietary fibre, sulphur, and sulphate intake in turn. These were chosen to limit the number of dietary variables that were being tested while being comprehensive and including foods for which a reasonable

Table 2 Association of dietary intake of food groups and relapse in ulcerative colitis

\begin{tabular}{|c|c|c|c|c|c|c|c|}
\hline & \multirow{2}{*}{\multicolumn{2}{|c|}{ Median daily consumption (g) }} & \multicolumn{3}{|c|}{$\begin{array}{l}\text { Categorical analysis (comparing tertiles to tertile of } \\
\text { lowest dietary intake) }\end{array}$} & \multirow{2}{*}{\multicolumn{2}{|c|}{$\begin{array}{l}\text { Continuous analysis } \\
\text { Linear trend }\end{array}$}} \\
\hline & & & \multirow{2}{*}{$\begin{array}{l}\text { Medium intake } \\
\text { OR }(95 \% \mathrm{Cl})\end{array}$} & \multirow{2}{*}{$\begin{array}{l}\text { High intake } \\
\text { OR }(95 \% \mathrm{Cl})\end{array}$} & \multirow[b]{2}{*}{ LRT $p$} & & \\
\hline & Relapse & Non-relapse & & & & $\mathrm{OR} / 10 \mathrm{~g}$ & $(95 \%$ Cl) \\
\hline Cereals and cereal products & 256 & 259 & $0.82(0.37-1.82)$ & $1.04(0.46-2.35)$ & 0.816 & 1.01 & $(0.99-1.04)$ \\
\hline Milk and milk products & 221 & 201 & $1.17(0.53-2.59)$ & $1.33(0.60-2.97)$ & 0.779 & 1.00 & $(0.99-1.02)$ \\
\hline Eggs & 16 & 13 & $1.78(0.80-3.98)$ & $2.26(1.01-5.08)$ & 0.119 & 1.05 & $(0.94-1.18)$ \\
\hline Vegetables & 334 & 345 & $0.68(0.30-1.53)$ & $1.12(0.50-2.52)$ & 0.439 & 1.01 & $(0.98-1.03)$ \\
\hline Fruit & 220 & 260 & $0.98(0.44-2.19)$ & $0.79(0.35-1.79)$ & 0.818 & 1.00 & $(0.98-1.02)$ \\
\hline Fish and fish products & 32 & 35 & $1.52(0.67-3.46)$ & $1.26(0.56-2.81)$ & 0.602 & 1.02 & $(0.94-1.11)$ \\
\hline Meat and meat products & 195 & 146 & $1.37(0.60-3.13)$ & $3.20(1.31-7.79)$ & 0.027 & 1.08 & $(1.03-1.12)$ \\
\hline Red and processed meat & 172 & 124 & $2.16(0.93-4.98)$ & $5.19(2.09-12.9)$ & 0.001 & 1.10 & $(1.05-1.15)$ \\
\hline Non-alcoholic beverages & 1434 & 1260 & $0.97(0.44-2.13)$ & $1.63(0.73-3.61)$ & 0.361 & 1.00 & $(1.00-1.01)$ \\
\hline Alcoholic beverages & 238 & 150 & $0.80(0.35-1.82)$ & $2.71(1.10-6.67)$ & 0.017 & 1.01 & $(1.00-1.02)$ \\
\hline Sugars, preserves, and snacks & 44 & 54 & $1.29(0.58-2.87)$ & $0.94(0.42-2.12)$ & 0.723 & 1.01 & $(0.94-1.08)$ \\
\hline
\end{tabular}


Table 3 Association of medium and high (versus lowest tertile) macronutrient and food constituent intake and relapse in ulcerative colitis

\begin{tabular}{|c|c|c|c|c|c|c|c|}
\hline & \multicolumn{2}{|c|}{ Median daily consumption } & \multicolumn{3}{|c|}{$\begin{array}{l}\text { Categorical analysis (comparing tertiles to tertile of lowest } \\
\text { dietary intake) }\end{array}$} & \multicolumn{2}{|c|}{ Continuous analysis } \\
\hline & Relapse & Non-relapse & $\begin{array}{l}\text { Medium intake } \\
\text { OR }(95 \% \mathrm{Cl})\end{array}$ & $\begin{array}{l}\text { High intake } \\
\text { OR }(95 \% \mathrm{Cl})\end{array}$ & LRT p & $\mathrm{OR}^{*}$ & $95 \% \mathrm{Cl}$ \\
\hline \multicolumn{8}{|l|}{ Macronutrients } \\
\hline Energy (kJ) & 11567 & 10657 & $1.32(0.57-3.06)$ & $2.81(1.14-6.93)$ & 0.053 & 1.01 & $1.00-1.02$ \\
\hline Fat $(\mathrm{g})$ & 100 & 94 & $1.30(0.57-2.96)$ & $2.52(1.06-5.97)$ & 0.085 & 1.06 & $0.99-1.13$ \\
\hline Fibre (g) & 21 & 22 & $1.06(0.31-3.70)$ & $0.88(0.34-2.29)$ & 0.916 & 1.08 & $0.76-1.55$ \\
\hline Carbohydrate (g) & 291 & 319 & $0.94(0.41-2.14)$ & $1.31(0.56-3.06)$ & 0.698 & 1.02 & $0.99-1.05$ \\
\hline Protein $(g)$ & 97 & 88 & $1.38(0.60-3.15)$ & $3.00(1.25-7.19)$ & 0.034 & 1.13 & $1.01-1.26$ \\
\hline Alcohol (g) & 14 & 10 & $1.21(0.53-2.79)$ & $2.42(1.04-5.62)$ & 0.088 & 1.19 & $1.01-1.41$ \\
\hline \multicolumn{8}{|l|}{ Food constituents } \\
\hline $\begin{array}{l}\text { Non-starch } \\
\text { polysaccharide (a) }\end{array}$ & 16.4 & 16.3 & $1.07(0.48-2.39)$ & $1.14(0.51-2.55)$ & 0.954 & 1.18 & $0.76-1.83$ \\
\hline Sulphur (mg) & 396 & 350 & $1.28(0.57-2.87)$ & $2.76(1.19-6.40)$ & 0.039 & 1.02 & $1.00-1.05$ \\
\hline Sulphate (mg) & 668 & 636 & $1.45(0.64-3.30)$ & $2.61(1.08-6.30)$ & 0.089 & 1.02 & $1.00-1.04$ \\
\hline
\end{tabular}

hypothesis existed to associate them with modified disease activity. For each of these food stuffs, median intakes in the remission and relapse categories are presented (tables 2, 3). Also presented from the multivariate analyses are the ORs for relapse, adjusted for SCCAI, age, and sex, comparing medium and high intake tertiles with low tertile and ORs and corresponding confidence intervals for a linear term (tables 2, 3). A high intake of meat and meat products (particularly red and processed meats), eggs, protein, alcohol, energy, fat, sulphur, and sulphate predicted an increased likelihood of relapse.

Because $23 \%$ patients appeared to underreport or overreport energy intake based on PAL, analyses of the significant dietary factors were repeated including only those 122 patients whose PAL fell within the acceptable limits of 1.14-2.11. Relapse was still associated with a high intake of meat (OR compared with low intake 3.74 (95\% CI 1.1212.6)), particularly red and processed meat (OR 6.88 (95\% CI 2.02-23.4)) and alcohol (OR 4.14 (95\% CI 1.14-15.0)). No other dietary factors were statistically significant.

All models were a reasonable fit to the observed data, with the exception of the continuous analysis of the effect of dietary intake of non-alcoholic beverages (for which a reasonable fit was obtained once a non-linear term for intake was included in the model).

\section{DISCUSSION}

In this prospective cohort study, it was confirmed that preceding increased disease activity is associated with an increased risk of relapse. Importantly, potentially modifiable dietary factors were also identified that were associated with an increased risk of relapse of UC. The strongest relationship between a dietary factor and an increased risk of relapse observed in this study was for a high intake of meat, particularly of red meat and processed meat. This is a novel finding. Consumption of large amounts of sulphur and sulphate were also associated with an increased risk of relapse, and although they may have been spurious findings due to the number of statistical tests performed, these components of food may offer an explanation for the increased risk seen with meat. Red meat, for instance, is stated as a food to be avoided on a low sulphur amino acid $\operatorname{diet}^{28}$ and processed foods contain large amounts of sulphate as a food additive. ${ }^{23}$ Similarly, a high alcohol intake was associated with an increased risk of relapse and many alcoholic drinks contain large amounts of sulphates as additives. ${ }^{23} \mathrm{~A}$ high sulphur diet, either from sulphur amino acids or sulphate additives, results in the generation of hydrogen sulphide ${ }^{2627}$ and mucosal damage in the colon.

Contrary to beliefs commonly held by patients, no association was detected between increased intake of milk or dairy products and relapse, and no apparent protective effect of an increased intake of dietary fibre.

The strengths of this study are that the study design removed the possibility of recall bias and minimised misclassification bias by being a prospective study; a dietary assessment tool (FFQ plus a validated food photograph atlas) and a validated disease activity index were used to assess baseline habitual dietary intake and disease outcome; there was a very low dropout rate and the statistical analysis controlled for non-dietary differences between patients who did and did not relapse.

There are some potential criticisms of the dietary assessment tool. It has been suggested that FFQs overestimate habitual energy intake $e^{52}$ and on initial inspection this would appear to be the case in this study as more patients overestimated than underestimated energy intake based on PAL. However, this may have been a reflection of their true requirements because subjects had a higher than expected energy expenditure related to subclinical disease activity or previous weight loss and subsequent catch-up from earlier relapses. Habitual diet was assessed at only one time point for each individual and therefore recall of the immediate diet by participants was prone to reflect small seasonal differences or recent special occasions. However, the global market has made foods previously considered to be seasonal available most of the year and studies to determine the effect of season on intake have shown little impact on nutrient intake. ${ }^{54}$ Also, as a prospective cohort study there is no reason to consider that errors in reporting of diet would be more common among either relapsers or those who remained in remission.

A further potential criticism of the study is that sigmoidoscopy was not performed to confirm relapses nor were stool samples analysed to exclude an infective agent. However, the activity index used had been shown in a separate cohort to accurately predict a relapse of UC, which was defined by a clinician and included examination of the rectal mucosa in some cases. It would be impossible to exclude a small number of cases being misclassified using this (or any other noninvasive) method but for a population the method of defining relapse has been validated, in much the same way as the Crohn's disease activity index does not use endoscopic confirmation. $^{55}$ Furthermore, examination of the rectal mucosa can also give false negative results as up to one 
third of patients with proximal inflammation of the colon have a non-inflamed rectal mucosa, ${ }^{56}$ particularly with the use of rectal treatments.

The main weakness of the study relates to data for sulphur and sulphate content of the diet rather than data for meat, protein, and alcohol content of foods, which are robust. Although data on the sulphur content of foods in the food tables are reliable, they are incomplete, with the majority of foods consumed by participants not having a sulphur content listed. Only foods or dishes containing fruit or nuts are allocated a sulphur content. ${ }^{41}$ However, as the sulphur composition of meat, which is known to be high, was missing from the food tables, and relapse was associated with a high consumption of meat and meat products, more complete food tables for sulphur would be expected to increase the differences in sulphur consumption between participants who did or did not relapse.

Similarly, there are limitations with the data on sulphate content of foods as they are based on one method of sulphate analysis, reported in one paper. This showed wide variation in sulphate content for certain foods (for instance, bread) depending on whether it was homemade or processed. Therefore, mean values for sulphate content of foods were used. Sulphate data, unlike sulphur data, were complete for virtually all foods consumed by the study subjects but their accuracy has not been independently validated. Sulphasalazine is also a potential source of "dietary" sulphate but as a sulphate ester it is unlikely that anionic sulphate is liberated because acid hydrolysis, comparative with the effect of gastric acid, does not release sulphate from sulphate esters. ${ }^{57}$ Furthermore, decreased levels of hydrogen sulphide production have been noted in patients taking 5-aminosalicylic acid drugs, including sulphasalazine, ${ }^{20}$ and few patients were taking sulphasalazine.

In summary, despite the inherent difficulties in the assessment and validation of nutritional intake, results from this observational cohort study suggest that certain dietary factors influence whether or not a patient with UC in remission is at increased risk of relapse. Dietary factors are less important statistically than measures of prior disease activity in determining the risk of relapse but clinically much more important because nutrient intake is potentially modifiable. A high meat, protein, or alcohol intake is associated with an increased risk of relapse which may well occur because these foods are rich sources of sulphur and sulphate which increase the concentration of faecal hydrogen sulphide that is toxic to the colonocyte. More comprehensive data on sulphur and sulphate contents of foods is required in order to gain further insights into the potential role of these nutrients in the aetiology of relapses of UC. In addition, an intervention study is needed before it could be concluded that sulphur and sulphate rich foods definitely increase the risk of relapse, and that a low meat and sulphur or sulphate diet negates that risk without significant side effects.

\section{ACKNOWLEDGEMENTS}

Northumbria Healthcare Trust funded Dr Sarah Jowett as a Teaching and Research Fellow. We would like to thank the patients who participated in this study over the course of a year.

\section{Authors' affiliations}

S L Jowett, J R Barton, M R Welfare, Northumbria Division of the University of Newcastle upon Tyne Faculty of Medicine, Newcastle upon Tyne, UK

C J Seal, Human Nutrition Research Centre, School of Agriculture, Food and Rural Development, University of Newcastle upon Tyne, Newcastle upon Tyne, UK

M S Pearce, Paediatric and Lifecourse Epidemiology Research Group, School of Clinical Medical Sciences, University of Newcastle upon Tyne, Newcastle upon Tyne, UK
E Phillips, W Gregory, Department of Medicine, Northumbria Healthcare Trust, Newcastle upon Tyne, UK

\section{REFERENCES}

1 Langholz E, Munkholm P, Davidsen M, et al. Course of ulcerative colitis: analysis of changes in disease activity over years. Gastroenterology 1994;107:3-11.

2 Bitton A, Peppercorn MA, Antonioli DA, et al. Clinical, biological, and histologic parameters as predictors of relapse in ulcerative colitis. Gastroenterology 2001;120:13-20.

3 Riley SA, Mani V, Goodman MJ, et al. Why do patients with ulcerative colitis relapse? Gut 1990;31:179-83.

4 Leo S, Leandro G, Di Matteo G, et al. Ulcerative colitis in remission: it is possible to predict the risk of relapse? Digestion 1989;44:217-21.

5 Geerling BJ, Dagnelie PC, Badart-Smook A, et al. Diet as a risk factor for the development of ulcerative colitis. Am J Gastroenterol 2000;95:1008-13.

6 Russel MG, Engels LG, Muris JW, et al. 'Modern life' in the epidemiology of inflammatory bowel disease: a case-control study with special emphasis on nutritional factors. Eur J Gastroenterol Hepatol 1998; 10:243-9.

7 Reif S, Klein I, Lubin F, et al. Pre-illness dietary factors in inflammatory bowel disease. Gut 1997;40:754-60.

8 Tragnone A, Valpiani D, Miglio F, et al. Dietary habits as risk factors for inflammatory bowel disease. Eur J Gastroenterol Hepatol 1995;7:47-51.

9 Persson PG, Ahlbom A, Hellers G. Diet and inflammatory bowel disease: a case-control study. Epidemiology 1992;3:47-52.

10 Wright R, Truelove SC. A controlled therapeutic trial of various diets in ulcerative colitis. Br Med J 1965;2:138-42.

11 Samuelsson SM, Ekbom A, Zack M, et al. Risk factors for extensive ulcerative colitis and ulcerative proctitis: a population based case-control study. Gut $1991 ; 32: 1526-30$.

12 Davies PS, Rhodes J. Maintenance of remission in ulcerative colitis with sulphasalazine or a high-fibre diet: a clinical trial. Br Med J 1978;1:1524-5.

13 Mitsuyama K, Saiki T, Kanauchi O, et al. Treatment of ulcerative colitis with germinated barley foodstuff feeding: a pilot study. Aliment Pharmacol Ther 1998; 12:1225-30.

14 Fernandez-Banares F, Hinojosa J, Sanchez-Lombrana JL, et al. Randomized clinical trial of Plantago ovata seeds (dietary fiber) as compared with mesalamine in maintaining remission in ulcerative colitis. Spanish Group for the Study of Crohn's Disease and Ulcerative Colitis (GETECCU). Am J Gastroenterol 1999:94:427-33.

15 Ohkusa T. Production of experimental ulcerative colitis in hamsters by dextran sulfate sodium and changes in intestinal microflora. Jpn J Gastroenterol 1985;82:1327-36.

16 Roediger WE, Duncan A, Kapaniris $\mathrm{O}$, et al. Reducing sulfur compounds of the colon impair colonocyte nutrition: implications for ulcerative colitis. Gastroenterology 1993; 104:802-9

$17 \mathrm{Ng} \mathrm{W}$, Tonzetich J. Effect of hydrogen sulfide and methyl mercaptan on the permeability of oral mucosa. J Dent Res 1984;63:994-7.

18 Christl SU, Eisner HD, Dusel G, et al. Antagonistic effects of sulfide and butyrate on proliferation of colonic mucosa: a potential role for these agents in the pathogenesis of ulcerative colitis. Dig Dis Sci 1996;41:2477-81.

19 Aslam M, Batten JJ, Florin THJ, et al. Hydrogen sulphide induced damage to the colonic mucosal barrier in the rat. Gut 1992;33:S69.

20 Pitcher MC, Beatty ER, Cummings JH. The contribution of sulphate reducing bacteria and 5-aminosalicylic acid to faecal sulphide in patients with ulcerative colitis. Gut 2000:46:64-72.

21 Florin T, Gibson GR, Neale G, et al. A role for sulfate reducing bacteria in ulcerative colitis? Gastroenterology 1990;98:A170

22 Florin T, Neale G, Gibson GR, et al. Metabolism of dietary sulphate: absorption and excretion in humans. Gut 1991:32:766-73.

23 Florin THJ, Neale G, Goretski S, et al. The sulfate content of foods and beverages. J Food Composition Anal 1993;6:140-51.

24 Geypens B, Claus D, Evenepoel P, et al. Influence of dietary protein supplements on the formation of bacterial metabolites in the colon. Gut 1997;41:70-6.

25 Gibson GR, Cummings JH, Macfarlane GT. Use of a three-stage continuous culture system to study the effect of mucin on dissimilatory sulfate reduction and methanogenesis by mixed populations of human gut bacteria. Appl Environ Microbiol 1988;54:2750-5.

26 Magee EA, Richardson CJ, Hughes R, et al. Contribution of dietary protein to sulfide production in the large intestine: an in vitro and a controlled feeding study in humans. Am J Clin Nutr, 2000;72:1488-94.

27 Magee EAM, Richardson CJ, Cummings JH. Dietary precursors of sulphide in the human large intestine. Proc Nutr Soc 2001;60:16A

28 Roediger WE. Decreased sulphur aminoacid intake in ulcerative colitis. Lancet 1998:351:1555.

29 Nelson M, Atkinson M, Meyer J. Food portion sizes. A users guide to the photographic atlas. London: Ministry of Agriculture, Fisheries and Food, 1997.

30 Nelson M, Atkinson M, Meyer J. A photographic atlas of food portion sizes. London: Ministry of Agriculture, Fisheries and Food, 1997.

31 Ford C, Seal CJ, Milburn H, et al. Assessment of nutrient consumption in alcoholic patients using a food assessment questionnaire. Proc Nutr Soc 1997; 56:118A.

32 Broadhead EE, Hughes PM, Kelly CG, et al. Effects of radiotherapy treatment on dietary intake in patients with cancer of the head and neck. Proc Nutr Soc 2001;60:55A. 
33 Harris AM. The role of diet in the development of Barrett's oesophagus and oesophageal adenocarcinoma, MD Thesis. Newcastle upon Tyne: University of Newcastle upon Tyne, 2002.

34 Gregory J, Foster K, Tyler $\mathrm{H}$, et al. Dietary and nutritional survey of British adults. London: HMSO, 1990.

35 Nelson M, Atkinson M, Darbyshire S. Food Photography I. The perception of food portion size from photographs. Br J Nutr 1994;72:649-63.

36 Nelson M, Atkinson M, Darbyshire S. Food photography II: use of food photographs for estimating portion size and the nutrient content of meals. Br J Nutr 1996;76:31-49.

37 Holland B, Welch A, Unwin ID, et al. McCance and Widdowson's the composition of foods, 5th edn., Cambridge: Royal Society of Chemistry 1991.

38 Chan W, Brown J, Lees SM, et al. Meat, poultry and game: fifth supplement to the fifth edition of McCance and Widdowson's the composition of foods. Cambridge: Royal Society of Chemistry, 1995.

39 Chan W, Brown J, Buss DH. Miscellaneous foods: fourth supplement to the fifth edition of McCance and Widdowson's the composition of foods. Cambridge: Royal Society of Chemistry, 1994

40 Holland B, Brown J, Buss DH. Fish and fish products: third supplement to the fifth edition of McCance and Widdowson's the composition of foods. Cambridge: Royal Society of Chemistry, 1993.

41 Holland B, Unwin ID, Buss DH. Fruit and nuts: first supplement to the fifth edition of McCance and Widdowson's the composition of foods. Cambridge: Royal Society of Chemistry, 1992

42 Holland B, Welch A, Buss DH. Vegetable dishes: second supplement to the fifth edition of McCance and Widdowson's the composition of foods. Cambridge: Royal Society of Chemistry, 1992.

43 Committee on Medical Aspects of Food Policy and Panel on Dietary Reference Values. Dietary reference values for food energy and nutrients for the United Kingdom, 41. London: HMSO, 1991.

44 Goldberg GR, Black AE, Jebb SA, et al. Critical evaluation of energy intake data using fundamental principles of energy physiology: 1. Derivation of cutoff limits to identify under-recording. Eur J Clin Nutr 1991;45:569-81.
45 Sanchez-Castillo CP, Franklin M, McNeill G, et al. Are the proposed limits of energy intake:basal metabolic rate and dietary nitrogen:urinary nitrogen ratios suitable for validation of food intake? Br J Nutr 2001;85:725-31.

46 Walmsley RS, Ayres RC, Pounder RE, et al. A simple clinical colitis activity index. Gut 1998;43:29-32.

47 Jowett SL, Seal CJ, Phillips E, et al. Defining relapse of ulcerative colitis using a symptom-based activity index. Scand J Gastroenterol 2003;38:164-71.

48 Sempos CT, Liu K, Ernst ND. Food and nutrient exposures: what to consider when evaluating epidemiologic evidence. Am J Clin Nutr 1999;69:1330S-8.

49 Willett WC, Stampfer MJ, Colditz GA, et al. Relation of meat, fat, and fiber intake to the risk of colon cancer in a prospective study among women. N Engl J Med 1990;323:1664-72.

50 Michels KB, Rosner BA. Data trawling: to fish or not to fish. Lancet 1996;348: 1152-3.

51 Rothman KJ. No adjustments are needed for multiple comparisons. Epidemiology 1990;1:43-6.

52 Pietinen P, Hartman AM, Haapa E, et al. Reproducibility and validity of dietary assessment instruments. I. A self-administered food use questionnaire with a portion size picture booklet. Am J Epidemiol 1988;128:655-66.

53 Andersen LF, Nes M, Lillegaard IT, et al. Evaluation of a quantitative food frequency questionnaire used in a group of Norwegian adolescents. Eur J Clin Nutr 1995;49:543-54.

54 Hartman AM, Block G, Chan W, et al. Reproducibility of a self-administered diet history questionnaire administered three times over three different seasons. Nutr Cancer 1996;25:305-15.

55 Best WR, Becktel JM, Singleton JW, et al. Development of a Crohn's disease activity index. National Cooperative Crohn's Disease Study. Gastroenterology 1976;70:439-44.

56 Holmquist L, Ahren C, Fallstrom SP. Clinical disease activity and inflammatory activity in the rectum in relation to mucosal inflammation assessed by colonoscopy. A study of children and adolescents with chronic inflammatory bowel disease. Acta Paediatr Scand 1990;79:527-34.

57 Dodgson KS, White GF, Fitzgerald JW. Sulfatases of microbiol origin. Boca Raton: CRC Press, 1982.

\title{
EDITOR'S QUIZ: GI SNAPSHOT
}

\author{
Late complication of blunt abdominal trauma
}

Robin Spiller, Editor

\section{Clinical presentation}

A 34 year old man was evaluated in the emergency department for a two day history of abdominal pain, nausea, vomiting, dyspnoea, and breathlessness. He had a history of blunt abdominal trauma 13 years ago with recurrent symptoms of bowel obstruction resolving spontaneously. The patient reported having had bowel movements the morning of his presentation but no subsequent passing of flatus. His temperature was $37.3^{\circ} \mathrm{C}$ with slight sinus tachycardia (108/ $\mathrm{mn}$ ) and blood pressure of 100/60 $\mathrm{mm} \mathrm{Hg}$. He was lethargic but normally oriented. Physical examination revealed mild tenderness in the mid abdomen with absent bowel sounds. No breath sounds were heard in the left lower thorax. Laboratory work demonstrated elevated white blood cell count. Plain chest films obviated an elevated diaphragm bilaterally, more pronounced on the left side. A thoracoabdominal computed tomography scan study was undertaken (fig l).

\section{Question}

How can the left hemithorax content be related to the patient's complaints?

See page 1498 for answer

This case is submitted by:

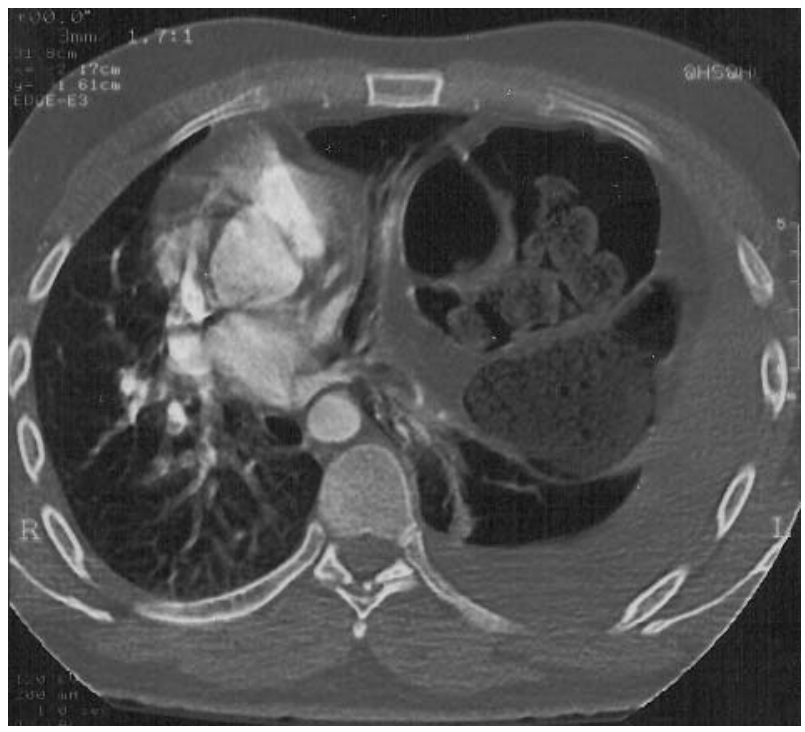

Figure 1 Thoracoabdominal computed tomography scan.

B Abboud, G Sleilaty

Department of General Surgery, Hotel Dieu de France Hospital, Faculty of Medicine, Saint-Joseph University, Beirut, Lebanon

J B Jaoude

Department of Gastroenterology, Hotel Dieu de France Hospital, Faculty of Medicine, Saint-Joseph University, Beirut, Lebanon

M Riachi

Department of Pneumology and Intensive Care Unit, Hotel Dieu de France Hospital, Faculty of Medicine, Saint-Joseph University, Beirut, Lebanon

G Tabet

Department of Thoracic and Cardiovascular Surgery, Hotel Dieu de France Hospital, Faculty of Medicine, Saint-Joseph University, Beirut, Lebanon

Correspondence to: $\operatorname{Dr} B$ Abboud, Department of General Surgery, Hotel Dieu de France Hospital, Alfred Naccache Street, Beirut, Lebanon; dbabboud@yahoo.fr

doi: $10.1136 /$ gut.2003.034801 